\title{
GCU
}

Glasgow Caledonian

University

University for the Common Good

\section{Considering social enterprise involvement in the commissioning of health services in Shetland}

Macaulay, Bobby

Published in:

Local Economy

DOI:

$10.1177 / 0269094216655405$

Publication date:

2016

Document Version

Author accepted manuscript

Link to publication in ResearchOnline

Citation for published version (Harvard):

Macaulay, B 2016, 'Considering social enterprise involvement in the commissioning of health services in Shetland', Local Economy, vol. 31, no. 5, pp. 650-659. https://doi.org/10.1177/0269094216655405

\section{General rights}

Copyright and moral rights for the publications made accessible in the public portal are retained by the authors and/or other copyright owners and it is a condition of accessing publications that users recognise and abide by the legal requirements associated with these rights.

Take down policy

If you believe that this document breaches copyright please view our takedown policy at https://edshare.gcu.ac.uk/id/eprint/5179 for details of how to contact us. 
In Perspective: Considering social enterprise involvement in the commissioning of health services in Shetland

\author{
Bobby Macaulay
}

Yunus Centre for Social Business and Health, Glasgow Caledonian University, Glasgow, UK

Cowcaddens Road, Glasgow, G4 0BA

\title{
bobby.macaulay@gcu.ac.uk
}

This work was supported by the Medical Research Council and the Economic and Social Research Council: grant number MR/L003287/1

Authors' Pre-publication version - cite as:

Macaulay, B. (2016) 'In Perspective: Considering social enterprise involvement in the commissioning of health services in Shetland'. Local Economy 


\section{Abstract}

Social enterprises are increasingly becoming involved in the commissioning of health services as the NHS in Scotland seeks more efficient and effective ways to care for an ageing population in a period of austerity. This development is of particular importance in rural areas where health services are being disproportionately affected due to funding cuts and health outcomes are suffering as a result.

A geographic area of interest in terms of the inclusion of social enterprise in health strategies is Shetland. As a remote island group, different solutions to the provision of health services are required due to often inaccessible, illequipped and expensive statutory services. A history of available funding and ample volunteers has created a strong third sector that is able and willing to provide health services and which is increasingly adopting trading practices to ensure sustainability as non-traded income becomes scarcer.

This research investigated the role currently played by social enterprises in the co-governance and co-management of health services in Shetland, what factors influence that involvement and how successful the commissioning process is seen to be. The findings shed light on the current role that social enterprises play in designing, delivering and managing health services in Shetland with implications for other rural and remote communities in Scotland. 
Keywords: social enterprise, public health, commissioning, co-production

\section{Introduction}

In recent years the National Health Service (NHS) in Scotland has experienced the increasing burden of caring for an ageing population, an economic recession and cuts in public spending, leading to an increasing interest in delivering health services in more efficient and effective ways (Scottish Government, 2011).

The intention of this research was to investigate the current nature of the commissioning process in Shetland in regard to the co-governance and comanagement of health services between the public sector and social enterprises. The research considered whether the relationship could be a solution to both the sustainable funding of social enterprises, and the provision of adequate health services in Shetland. 


\section{Background}

\section{Third Sector Organisations and Public Sector Partnerships}

For decades, third sector organisations ${ }^{1}$ (TSOs) filled the gap between public and private sector provision of health and social services, but the increasing size of this gap has placed extra responsibility in the hands of the third sector without being matched by increased funding (Dickinson et al., 2012). This has led some TSOs to curb their activities or be stretched beyond capacity, disproportionately impacting upon the groups which are often the focus of TSOs, namely: vulnerable, stigmatised or 'hard to reach' groups; and rural and remote communities, which could be at risk of not being catered for at all (Gibbins, 2009). Other organisations have attempted to supplement their non-traded income with traded-income, in an attempt to match extra responsibilities with additional funding (Hill, 2012). Such organisations have diversified into selling goods and services to help fund (and sometimes simultaneously enhance) their work, and contracting with the public sector. In England, organisations are increasingly becoming involved in delivery of health and social care, representing a potential solution to both continued delivery of

\footnotetext{
1 'Third Sector' is a vague and contested term. While the Scottish Government retains the use of the term, the UK Government now increasingly refers instead to 'civil society' and includes within it 'voluntary and community organisations, charities, mutual and social enterprises' (Dickinson et al., 2012). For the purposes of this research, 'TSOs' will be used to incorporate these organisations.
} 
those services and future funding of TSOs (Millar et al., 2013). This has coincided with an increasing trend within the Scottish policy environment towards partnership working within health and care service delivery (Munoz, 2013). Such services include provision of home care, cleaning and maintenance, and catering, but could potentially include any element of 'preventative' or 'social' care (Munoz, 2011: 44).

The term commonly used for the process of involving the third sector in design and delivery of public services is 'co-production', although this ambiguous term has confusingly also been used to describe direct citizen involvement in the process (Brandsen and Pestoff, 2006). Debates surrounding the term are outside the scope of this research. For the purposes of this paper, 'co-production' will be used to refer to the latter process - 'an arrangement where citizens produce their own services at least in part' (Brandsen and Pestoff, 2006: 497). Co-production, 'co-governance' ('an arrangement in which the third sector participates in the planning and delivery of public services') and 'co-management' ('an arrangement in which the third sector produces services in collaboration with the state'), represent ways in which citizens and the third sector cooperate and collaborate with the public sector (Brandsen and Pestoff, 2006: 497). This paper explores the latter two elements, considering the ways in which TSOs interact with the public sector to design and deliver health services. 
Despite having provided services to people and communities for centuries, the formal integration of TSOs into 'provision of public services' is a relatively new development in the UK, having been introduced in the 1990s. Evidence of its impact is relatively scarce (Osborne and McLaughlin, 2004). 'Public services' can consist of the delivery of any form of public sector provision, but, in regard to TSOs, focuses predominantly on delivery of social care services and management of health promotion initiatives (Brandsen and Pestoff, 2006). As the language of collaboration between public and third sectors moves towards 'commissioning', the relationship itself relies ever more heavily on the delivery of outcomes, and increasingly resembles a contracting relationship, with services being 'privatised' and organisations 'selling' services to the public sector (Rees, 2014). Due to this, entities which may have previously considered themselves community, voluntary or charitable organisations, receiving non-traded grant income, are sometimes considered 'social enterprises' - a subset of the third sector, differentiated from other organisations by incorporating a 'trading element'.

Social enterprises are defined by the UK Department of Business, Innovation and Skills as: "a business with primarily social objectives whose surpluses are principally reinvested for that purpose in the business or in the community, rather than being driven by the need to maximise profit for 
shareholders and owners" (Department of Business, Innovation and Skills, 2011: 2). Despite this, there is considerable divergence in views on what can be considered a social enterprise and the definitional issue remains contentious (Teasdale, 2012). In Scotland, the prevailing definition requires that all profits are reinvested into social goals with none being returned to shareholders (Senscot, 2010).

\section{Social Enterprise and Rural Health}

Rural social enterprise development is seen to be facilitated through a variety of means, including: a culture of self-help, the likelihood of people knowing each other and their particular needs, willingness to help address those needs, and the tendency for rural social enterprises to stay small and flexible (Steinerowski and Steinerowska-Streb, 2012). A number of papers have been written on possible applications of social enterprises to improve health in Scotland, focusing on theoretical potential (Roy et al., 2014), policy implications (Donaldson et al., 2011; Roy et al., 2013) and a limited number of case studies (Boswell et al., 2009; Farmer et al., 2012a; McDermid et al., 2008; Westwater, 2009). It is claimed that social enterprises, like other third sector organisations, are able to interact with service users in a different manner to the public or private sector (Billis and Glennerster, 1998) due to the structure and culture of 
the organisation, and the 'policy context created by central and local government' (Dickinson et al., 2012; Osborne et al., 2008).

Studies on rural health tend to focus on the role of social enterprise in service delivery (Eversole et al., 2014; Farmer and Bradley, 2012) due in part to 'inefficient and sporadic' (Boswell et al., 2009: 4) health service provision in rural areas. Social enterprises have assumed control over statutory services in a number of cases and are seen to benefit communities simply through their presence within them (Steinerowski and Steinerowska-Streb, 2012).

Studies suggest that increased community participation in designing and delivering local health services has a positive effect on health outcomes (Farmer and Nimegeer, 2014). This is especially visible in rural areas which may require context-specific services reflecting the particular health needs of the community (Farmer et al., 2012b).

However, caution has been advised when advocating delivery of health services outside the public sector, due to the detrimental effect it could have on communities and service provision (Backman and Smith, 2000). It is claimed that increasing responsibility for solving complex health issues is being placed in the hands of individuals and communities (who may not have the means to solve them) for reasons of political ideology rather than effective or efficient provision (Friedli, 2013). This shift could jeopardise the distinctiveness of the 
sector, turning innovative organisations into simply vehicles for service delivery, and without the oversight of the local authority (Osborne et al., 2008).

\section{The Shetland Context}

Shetland comprises fifteen inhabited islands, varying in size and population and linked by bridges and car ferries. The population is estimated at 22,500 with around one third living in the main town, Lerwick. At $1.3 \%$, unemployment is substantially lower than the Scottish average with the public sector accounting for $32 \%$ of all employment in the isles, 11 percentage points higher than the national average (National Statistics, 2015; Shetland Islands Council, 2012).

Shetland suffers from many of the same health issues as other rural areas, with income and health inequalities (Smith et al., 2008) and a shrinking health sector (Gibbins, 2009; Hill, 2012; Shetland Islands Council, 2012). Although this does not necessarily lead to poorer health, it can have detrimental effects on emergency care (Panelli et al., 2006) and community sustainability (Farmer et al., 2012c).

The third sector in Shetland has been maintained at a large scale for decades, boasting more voluntary organisations and more volunteers per head of population than anywhere else in Scotland (Woolvin, 2012). This can be attributed predominantly to the availability of funding from the Shetland 
Charitable Trust (SCT), a fund established to distribute payments from the oil industry for the benefit of islanders (Anderson Solutions, 2011). In recent years, funding from both Shetland Islands Council (SIC) and SCT has been cut, affecting some organisations' abilities to deliver services and forcing some to downsize or close. Others have explored the possibility of generating revenue through selling products or services, or delivering commissioned services for the local authority or NHS Shetland, potentially increasing the size of the social enterprise sector in Shetland (Anderson Solutions, 2011). From 2014-2015, the integrated Health and Social Care Partnership between NHS Shetland and the Shetland Islands Council commissioned $£ 2.7 \mathrm{~m}$ worth of services from the third sector in Shetland, representing almost $6 \%$ of its total expenditure over that period (NHS Shetland, 2014).

\section{Methodology}

The approach taken to investigate the role of social enterprise in the cogovernance and co-management of health services in Shetland aimed to gather the views and opinions of a range of different stakeholders. A total of 11 semistructured qualitative interviews were conducted with community stakeholders and individuals involved in leading, working and volunteering in social enterprises in Shetland. The research was conducted between August 2014 
and February 2015 as part of a wider study investigating the extent to which social enterprise can be considered a public health 'intervention'.

\section{Interviews with Community Stakeholders}

Key local stakeholders were selected according to their seniority in the fields of public health, the voluntary sector and economic development. Interview topic guides covered: the size and capabilities of the social enterprise sector, factors enabling and constraining its development, and the nature of interactions between social enterprises and the public sector.

\section{Social Enterprise Case Studies}

Following consultation with community stakeholders, two organisations were selected as case studies due to their potential as 'data-rich' respondents. Interviews with leaders, staff and service users were sought, in an attempt to triangulate responses and to compare and contrast the thoughts of each group. Following initial verbal consent to take part, one of the organisations subsequently withheld consent to act as a gatekeeper for the interviewing of

\footnotetext{
${ }^{2}$ The research formed part of the CommonHealth Project ('Developing methods for evidencing social enterprise as a public health intervention'), based at Glasgow Caledonian University. The research was also used as part of the author's final dissertation for an MSc in Sustainable Rural Development at the University of the Highlands and Islands, entitled The role of social enterprise in improving health in Shetland.
} 
service users, although interviews with the leader and support worker were permitted.

Interview topic guides were designed with reference to the literature as well as the results of the stakeholder interviews. Topics covered included: the aims, activities and perceived outcomes of the social enterprise, the social enterprise environment in Shetland, and specific questions regarding health improvement. Interviews with leaders and staff were conducted one-on-one on the site of the social enterprises.

Interviews with service users, all of whom were considered 'vulnerable adults', were arranged through a gatekeeper, in accordance with ethical procedures. All interviews with service users were conducted on the social enterprise site.

\section{Data Analysis}

Interviews were transcribed by the author. Data was coded according to broad themes found in the literature, while allowing for new themes to emerge, and managed using QSR NVivo 10 coding software. 


\section{Findings}

\section{Respondents}

Results were compiled from interviews with respondents listed in (Table 1).

\section{Table 1- Respondents}

\begin{tabular}{|c|c|}
\hline Type of respondent & Number of respondents \\
\hline Community Stakeholder & 3 \\
\hline Social Enterprise Leader & 3 \\
\hline Social Enterprise Support Worker & 2 \\
\hline Social Enterprise Service User & 3 \\
\hline
\end{tabular}

In order to maintain anonymity, names of respondents and organisations are not included in the findings.

\section{Self-Reliance}

A number of respondents commented on the culture of community selfreliance in Shetland, it having stemmed from a long history of not being able to rely on public sector support from London or Edinburgh. This tradition led to the establishment of formal or informal community organisations which were the precursors to today's social enterprises: 
"You kind of rely on communities... Shetlanders are quite resilient and they're used to having to do things for themselves and to work together with neighbours and other people in the community to deliver certain goals. And I think there's a strong community ethos there."

Community Stakeholder 3

This is offered as an explanation for the relative ease through which the social enterprise sector has been able to deliver health services as they have been doing so informally for many years previously.

\section{Co-governance}

Within co-governance are the separate strands of 'design' and 'delivery'. The majority of responses regarding the former related to power dynamics, while those regarding the latter centred around coherence of the broader public health strategy.

The model of partnership working adopted in Shetland ostensibly allows different organisations the opportunity to contribute to the policy agenda, including which deficits need to be addressed, the relative funding arrangements through which that can happen, and which organisation will take charge of that process: 
"There is an inherent value in its own right in co-production models, because they, by their very nature, involve a different set of power relationships... [Deciding] what's wrong or what's missing currently or what the needs are of the people that they know about, and then together agreeing what needs to be developed or done differently to meet those needs"

Community Stakeholder 2

Respondents claimed that this process leads to a more coherent health strategy which values the relative strengths of each organisation, and is seen as key to effective identification and addressing of health needs. In terms of service delivery, social enterprises were considered more flexible and able to cater to specific groups or communities of interest more effectively, without the burden of a large national bureaucracy constraining abilities to react to emerging circumstances (Community Stakeholder 2). However, respondents considered the public sector better at quality assurance and at providing many statutory, downstream services. It was considered indispensable in terms of being a 'safety net', both in terms of ensuring social enterprises can continue to provide a service, and for guaranteeing that service users are receiving a highquality service (Community Stakeholder 3).

As budgets tighten, social enterprises were increasingly being seen as a 
cheaper way of delivering legally-required statutory services (Community Stakeholder 3) while other services would simply not be provided by the public sector if social enterprises ceased to deliver them:

"So it wouldn't have got done I think for that reason, not because [the public sector] wouldn't have necessarily understood it was a need, but I don't think it would have filtered to the top of the priority list"

Community Stakeholder 2

\section{Co-Management}

Due to the relatively small size of the Shetland population, many of the individuals involved in commissioning of health services know each other in an informal, as well as a formal, capacity. This leads not only to good personal and professional relationships between those around the table, but also a deeper knowledge of the work they do and the outcomes they are capable of producing (Support Worker 1).

This has engendered deeper mutual trust, allowing organisations and sectors to share data and information for mutual benefit. For example, certain social enterprises are, dependent on consent, given access to the medical records of their service users, as well as the ability to collaborate with GPs to design and manage programmes to more-effectively maintain the wellbeing of 
service users, many of whom would otherwise be under the care of the public sector (Social Enterprise Leader 1).

\section{Impacts of commissioning process on social enterprises and the}

\section{community}

For some organisations, contracts for delivery of health services are relied upon for survival:

"I think some charities, depending on the charitable purpose, would struggle to work with trading opportunities that would meet their charitable objects, apart from Service Level Agreements"

Community Stakeholder 3

It was further claimed that these Service Level Agreements (SLAs) were perceived in the same way as a grant from the Shetland Islands Council or NHS Shetland (Community Stakeholder 1). Therefore, despite now being seen as trading entities, there was not necessarily any change in the culture of the third sector due to delivering these services. Despite the vital role these contracts play in sustaining organisations, there are barriers to expanding their provision: 
"There are services that are being delivered by the local authority that could be delivered by the voluntary sector under Service Level Agreements. And sometimes there's a barrier there and the barrier probably is the Local Authority don't want it. There's somebody there going to lose power or jobs. And that's what they're trying to protect"

Community Stakeholder 1

This suggests the potential for expanding social enterprise involvement in service delivery, but no political will to accompany it. Furthermore, where there is will for services to be contracted out from the public sector, social enterprises may be excluded from the tendering process due to the larger nature of the contracts:

"The challenge that a lot of the social enterprises have is that quite a lot of the procurement processes aren't really geared-up for social enterprises to bid for lots of the work, even smaller bits of work that could potentially become available"

Community Stakeholder 3

It was also claimed that asymmetric power relationships and reliance on funding could lead to the public sector taking advantage of organisations by not paying them adequately for services provided, or by devolving responsibility for 
'toxic' assets to organisations (Community Stakeholder 3). This sentiment reinforces the importance of recognising the capabilities and limitations of the work of the social enterprise sector, as well as the ability of the sector to have a say in the services they are delivering. Taken together, it could be claimed that this is not undue protectionism on the part of the Council, but an awareness of the limitations of small organisations and the added costs of breaking up large public sector contracts.

In terms of the health impact on the broader community, it was claimed that the trading nature of social enterprises (whether in the form of commissioned services or otherwise) had the potential to positively impact upon health due to the different power relationship it engenders within communities:

"Social enterprises have a different relationship with their communities and the power that comes from that... is a strength in public health terms in terms of strong communities... Traditional ways of donating to charity bring a whole set of big problems in themselves, and you can view them politically as quite paternalistic... so social enterprise models where the giving is part of a trade, has an extra dimension that I think is a value in itself" 
This underlies the claim that, not only can social enterprises enjoy a closer relationship with the community than the public sector, but also they have a more equitable relationship with service users than other, non-trading, third sector organisations.

\section{Discussion}

Despite the commissioning process being considered part of a 'transformationally different' public health system from the point of view of the NHS (Brandsen and Pestoff, 2006; Scottish Government, 2011), from the perspective of respondents, very little has changed in regard to behaviour or funding streams of social enterprises, countering the fear held by some that they would lose their essential attributes if they were formalised into 'the system' (Brandsen and Pestoff, 2006; Osborne et al., 2008). The social enterprise sector was involved in the co-governance of health services as it was recognised its collaboration in designing such services led to more effective identification of community needs (Steinerowski and Steinerowska-Streb, 2012) and more efficient service delivery (Kenny et al., 2013). An in-depth knowledge of, and commitment to, the Shetland community, as well as each other's strengths and weaknesses, allowed different parties and sectors to interact effectively in the development of a coherent health strategy for the isles (Hills et al., 2010). 
Concerns were raised among some respondents that following the devolution of power to social enterprises, should they cease to deliver many of these services, the public sector would not 'take up the slack', although it was generally accepted that another TSO eventually would. Furthermore, it was feared the balance of power within the commissioning process could detrimentally affect organisations by potentially devolving responsibility for costly services to social enterprises without adequate recompense. These criticisms reflect claims that responsibility for public service delivery was being shifted from the public to the third sector due to political ideology, rather than effective service delivery (Friedli, 2013). However, social enterprises themselves claim that not enough services are being contracted out to social enterprises, reflecting a healthy enthusiasm for the continued culture of commissioning.

\section{Conclusion}

There is great belief in the capacity of Shetland's social enterprises to effectively design and provide services in response to health needs in the isles. It could be claimed that this is because social enterprises (and their predecessors) have been fulfilling these functions long before the public sector's involvement, and will continue to do so regardless of a re-definition of their role within service delivery or income generation. This form of collective 
self-reliance is seen as one of the benefits to social enterprises of working in rural areas and may also explain why such differentiated models of health service provision are claimed to be a 'better fit' in rural communities (Hill, 2012). The findings above suggest that a combination of these factors - the adequate identification of health needs in the community; the willingness for people and organisations to address those health needs; and the ability for those people and organisations to play an active role in directing health services towards those health needs - may explain the apparent success of social enterprises in the delivery of health services in Shetland (Steinerowski and SteinerowskaStreb, 2012). Fears regarding the retrenchment of the NHS and broader public sector, the increased responsibility placed on individuals and communities, and the power imbalances which may occur in the commissioning process, are also present in the isles. However, there is a great degree of confidence among respondents that the third sector in Shetland will provide the safety net required. The informal, as well as professional, relationships between those involved in the commissioning process forms both a social and contractual imperative to deliver the commissioned service, and to ensure safeguards are present to maintain its delivery.

More research is required to investigate further the relationship between community self-reliance, interactions between those involved in commissioning 
and provision of health services, and health outcomes to determine, for example, whether community self-reliance could be perceived as an antecedent to the effective functioning of the commissioning process in other regions.

\section{Funding}

This work was jointly supported by the Medical Research Council and Economic and

Social Research Council [grant number MR/L003287/1].

\section{References}

Anderson Solutions, 2011. Shetland Social Enterprise Review- Final Report. Anderson Solutions, Edinburgh.

Backman, E.V., Smith, S.R., 2000. Healthy organizations, unhealthy communities? Nonprofit Management and Leadership 10, 355-373.

Billis, D., Glennerster, H., 1998. Human Services and the Voluntary Sector: Towards a Theory of Comparative Advantage. Journal of Social Policy 27, 79-98. doi:10.1017/S0047279497005175

Boswell, J.P., Douglas, M.J., O’Neill, N.P., 2009. Health and Social Enterprise. Scottish Forum for Public Health. Available at:

https://www.google.co.uk/url?sa=t\&rct=j\&q=\&esrc=s\&source=web\&cd=1\&ved=0 ahUKEwiXpYm_IZ3NAhVpCcAKHU8MBe4QFggeMAA\&url=http\%3A\%2F\%2Fw ww.pathsforall.org.uk\%2Fcomponent $\% 2$ Foption $\% 2$ Ccom docman $\% 2$ Fltemid\% 2C69\%2Fgid\%2C374\%2Ftask\%2Cdoc_download\%2F\&usg=AFQjCNHUyKdR PHYuSsjZymqjfeQeBIUww\&sig2=Jj7-vxLbUU2mB2RYgwUfpg\&cad=rja

Brandsen, T., Pestoff, V., 2006. Co-production, the third sector and the delivery of public services: An introduction. Public Management Review 8, 493-501. doi:10.1080/14719030601022874

Department of Business, Innovation and Skills, 2011. A guide to legal forms for social enterprise. Department of Business, Innovation and Skills, London. 
Dickinson, H., Allen, K., Alcock, P., Macmillan, R., Glasby, J., 2012. The role of the third sector in delivering social care. School for Social Care Research, London.

Donaldson, C., Baker, R., Cheater, F., Gillespie, M., McHugh, N., Sinclair, S., 2011. Social business, health and well-being. Social Business 1, 17-35. doi:10.1362/204440811X570545

Eversole, R., Barraket, J., Luke, B., 2014. Social enterprises in rural community development. Community Development Journal 49, 245-261. doi:10.1093/cdj/bst030

Farmer, J., Bradley, S., 2012. Measuring the value of social organisations as rural service providers, in: Farmer, J., Hill, C., Munoz, S.-A. (Eds.), Community CoProduction: Social Enterprise in Remote and Rural Communities. Edward Elgar, Cheltenham, UK.

Farmer, J., Hill, C., Munoz, S.-A., 2012a. Community Co-Production: Social Enterprises in Remote and Rural Communities. Edward Elgar, Cheltenham.

Farmer, J., Munoz, S.-A., Threlkeld, G., 2012b. Theory in rural health. Australian Journal of Rural Health 20, 185-189. doi:10.1111/j.1440-1584.2012.01286.x

Farmer, J., Nimegeer, A., 2014. Community participation to design rural primary healthcare services. BMC health services research 14, 130.

Farmer, J., Prior, M., Taylor, J., 2012c. A theory of how rural health services contribute to community sustainability. Social Science \& Medicine 75(10): 1903-1911.

Friedli, L., 2013. "What we"ve tried, hasn't worked': the politics of assets based public health. Critical Public Health 23, 131-145. doi:10.1080/09581596.2012.748882

Gibbins, R., 2009. Delivering for Remote and Rural Healthcare. NHS Scotland, Edinburgh.

Hill, C., 2012. The signs all point to community social enterprise- don't they?, in: Farmer, J., Hill, C., Munoz, S.-A. (Eds.), Community Co-Production: Social Enterprise in Remote and Rural Communities. Edward Elgar, Cheltenham, pp.1-23.

Hills, M., Carroll, S., Desjardins, S., 2010. Assets Based Interventions: Evaluating and Synthesizing Evidence of the Effectiveness of the Assets Based Approach to Health Promotion, in: Morgan, A., Davies, M., Ziglio, E. (Eds.), Health Assets in a Global Context. Springer New York, New York, NY, pp. 77-98. 
Kenny, A., Hyett, N., Sawtell, J., Dickson-Swift, V., Farmer, J., O’Meara, P., 2013. Community participation in rural health: a scoping review. BMC health services research 13,64 .

McDermid, L., Durie, S., McLean, J., Woodhouse, A., 2008. Making an Impact: Exploring how to measure the mental health impacts of working in a social firm. Edinburgh. Social Firms Scotland.

Millar, R., Hall, K., Miller, R., 2013. A Story of Strategic Change: Becoming a Social Enterprise in English Health and Social Care. Journal of Social Entrepreneurship 4, 4-22. doi:10.1080/19420676.2012.694371

Munoz, S.-A., 2013. Co-producing care services in rural areas. Journal of Integrated Care 21, 276-287. doi:10.1108/JICA-05-2013-0014

Munoz, S.-A., 2011. Health service provision through social enterprise Opportunities and barriers identified by social entrepreneurs and procurement professionals in the UK. The International Journal of Entrepreneurship and Innovation 12, 3953.

National Statistics, 2015. Public Sector Employment in Scotland. Scottish Government, Edinburgh.

NHS Shetland, 2014. Joint Commissioning and Integration Plan. Available at: http://www.shetland.gov.uk/community_care/documents/CC-18-Ax1.pdf

Osborne, S.P., Chew, C., McLaughlin, K., 2008. The once and future pioneers? The innovative capacity of voluntary organisations and the provision of public services: A longitudinal approach. Public Management Review 10, 51-70. doi:10.1080/14719030701763187

Osborne, S.P., McLaughlin, K., 2004. The Cross-Cutting Review of the Voluntary Sector: Where Next for Local Government- Voluntary Sector Relationships? Regional Studies 38, 571-580. doi:10.1080/0143116042000229320

Panelli, R., Gallagher, L., Kearns, R., 2006. Access to rural health services: Research as community action and policy critique. Social Science \& Medicine 62, 11031114. doi:10.1016/j.socscimed.2005.07.018

Rees, J., 2014. Public sector commissioning and the third sector: Old wine in new bottles? Public Policy and Administration 29, 45-63.

doi:10.1177/0952076713510345 
Roy, M.J., Donaldson, C., Baker, R., Kay, A., 2013. Social enterprise: New pathways to health and well-being. Journal of public health policy 34, 55-68.

Roy, M.J., Donaldson, C., Baker, R., Kerr, S., 2014. The potential of social enterprise to enhance health and well-being: A model and systematic review. Social Science \& Medicine 123, 182-193. doi:10.1016/j.socscimed.2014.07.031

Scottish Government, 2011. Annual report of the chief medical officer 2010. Scottish Government, Edinburgh.

Senscot, 2010. Voluntary Code of Practice for Social Enterprise in Scotland. The Social Enterprise Network Scotland (SENSCOT). Available at: http://senscot.org/docs/VoluntaryCodeofPractice.pdf

Shetland Islands Council, 2012. Shetland In Statistics. Shetland Islands Council, Lerwick.

Smith, K.B., Humphreys, J.S., Wilson, M.G.A., 2008. Addressing the health disadvantage of rural populations: How does epidemiological evidence inform rural health policies and research? Australian Journal of Rural Health 16, 5666. doi:10.1111/j.1440-1584.2008.00953.x

Steinerowski, A.A., Steinerowska-Streb, I., 2012. Can social enterprise contribute to creating sustainable rural communities? Using the lens of structuration theory to analyse the emergence of rural social enterprise. Local Economy 27, 167-182. doi:10.1177/0269094211429650

Teasdale, S., 2012. What's in a Name? Making Sense of Social Enterprise Discourses. Public Policy and Administration 27, 99-119. doi:10.1177/0952076711401466

Westwater, D., 2009. How does the social enterprise model fit with community-led health initiatives? Community Health Exchange. Available at:

http://www.chex.org.uk/media/resources/publications/briefings/How\%20does\%2 Othe $\% 20$ Social\%20Enterprise $\% 20$ model\%20fit\%20with\%20Commled\%20Health\%20aug\%202009.pdf

Woolvin, M., 2012. Mapping The Third Sector in Rural Scotland: An Initial Review of the Literature. The Scottish Government, Edinburgh. 